\title{
DE WACHTERS VAN VAN ROSSUM
}

De Utrechtse hoogleraar neuropathologie prof.dr. Adriaan van Rossum had een grote interesse in Aziatische kunst en was al vroeg begonnen met het verzamelen daarvan. Zijn eerste aankopen betroffen voorwerpen uit Japan, later gevolgd door voorwerpen uit andere Aziatische landen en Klein-Azië. Eigenlijk reisde Van Rossum het liefst binnen Europa. Japan en India heeft hij slechts eenmaal bezocht. Zijn moeder had tot haar $10^{e}$ jaar in Indonesië gewoond. Wellicht was het haar voorliefde voor Chinees porselein die de kiem legde voor Van Rossums latere belangstelling voor Aziatische kunstvoorwerpen.

Van Rossum had verder een brede belangstelling voor kunst en muziek in het algemeen en met name voor opera. Hij was een uitmuntend spreker en beschikte over grote didactische kwaliteiten. Hij woonde ruim 30 jaar met veel plezier en toewijding voor huis en tuin in zijn huis 'Leeuwenburg' aan de Vecht te Maarssen te midden van zijn verzamelde kunstvoorwerpen. Hij overleed in 2002 op 86-jarige leeftijd. Hij legateerde aan de Vereniging een kameel en twee wachters, alle drie graffiguren uit de Tang-dynastie (618-906). Helaas is de kameel te fragiel om te worden verplaatst en kan hij dus niet bewonderd worden op de tentoonstelling in Het Princessehof over de schenkergeschiedenis van onze vereniging. De militaire wachters staan daar gelukkig wel. In dit artikel wordt een korte beschrijving gegeven van dergelijke grafwachters.

\section{Grafgiften in het oude China}

Begrafenisrituelen en begrafenispraktijken hebben gedurende de gehele Chinese geschiedenis een rol van betekenis vervuld. Op grond van het geloof dat de overledene het leven voortzet in het hiernamaals werden de doden door de eeuwen heen omgeven met allerhande religieuze en praktische voorwerpen om zo de lichamelijke en geestelijke verzorging te waarborgen. Dit geloof en bijgevolg de gebruiken en grafgiften verschilden per tijdsgewricht. Zo werden de doden in de oudheid van de Shang- (1600-1050 v.Chr.) en de Zhou-tijd (1050-221 v.Chr.) begeleid door rituele bronzen offervaten. In de late Han-periode (25-220) kreeg een dode replica's van voorwerpen uit het dagelijks leven mee. Vanaf de $3^{\mathfrak{c}}$ eeuw tot het eind van de Tang-tijd werd de rol van bedienden en bewakers van de overledene sterk benadrukt door het plaatsen van graffiguren (afb. 1 en 2 ).

Dergelijke graffiguren dienden tot dagelijks nut van de overledene en benadrukten eveneens de status en de behoeften van de dode. Tegenwoordig vormen ze een treffende illustratie van het toenmalige leven van de wel-

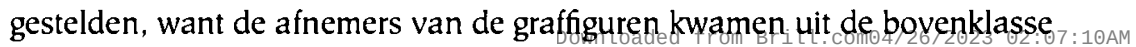
van de maatschappij. 
Afbeelding 1 (links) Grafwachters, grijszwarte klei - gebakken, hoogte $43 \mathrm{~cm}$., ZuidChina, oostelijke Jindynastie (317-420). Uit: Hájek en Forman, A book of Chinese art.

\section{Afbeelding 2}

Militaire grafwachter, licht aardwerk met verfresten - gebakken, hoogte 28-40 cm., Noord-China, gevonden in een graf in Beiyuan, noordelijke Wei-

dynastie (368-535). Uit:

Sanqin guibao. Shaanxi xin faxian wenwu jinghua.

Afbeelding 3 (pag. 74) Militaire grafwachter, aardewerk met sancaiglazuur, hoogte $85 \mathrm{~cm}$., China, Tang-dynastie. Legaat van A. van Rosum in 2002, Rijksmuseum Amsterdam, collectie VVAK, AK-MAK-1716

Afbeelding 4 (pag. 75) Militaire grafwachter, aardewerk met sancaiglazuur, hoogte $85 \mathrm{~cm}$., China, Tang-dynastie. Legaat van A. van Rosum in 2002, Rijksmuseum Amsterdam, collectie WAK, AK-MAK-17
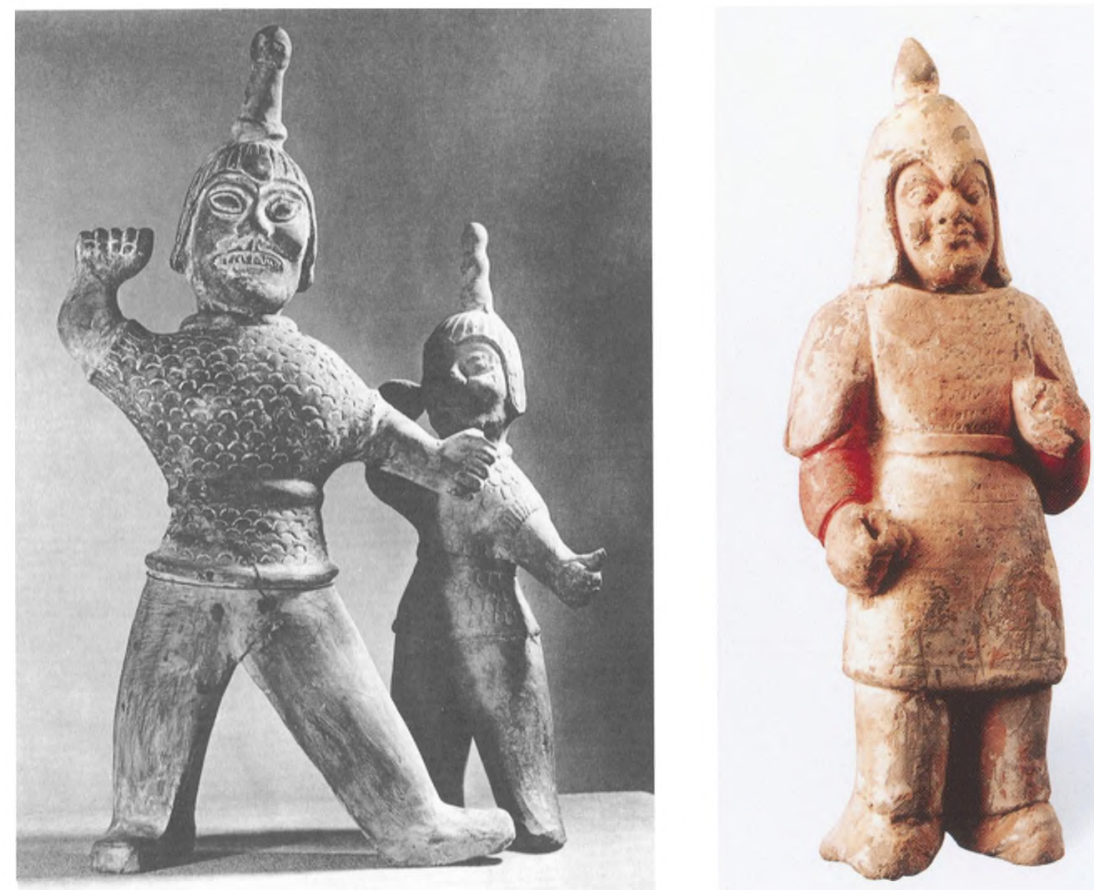

In de Tang-periode stelde de wet dat het graf van een overledene boven een zekere rang mocht worden voorzien van een groep figuren bestaande uit drie paren, militairen, ambtenaren en bovennatuurlijke wezens, die aan de ingang van het graf stonden om schadelijke invloeden af te wenden. Ze werden doorgaans in nissen geplaatst bij de opening van het hoofdgraf, en soms binnen het graf. De figuren waren zowel uit de boeddhistische wereld afkomstig als uit de seculiere wereld. Die aardewerken graffiguren waren gemodelleerd naar de stenen beelden die geplaatst werden op de shendao (de weg van de geest), de weg die naar het graf leidde, die in de Tang-tijd alleen voor keizers werd aangelegd.

\section{Ateliers}

Het vervaardigen van graffiguren was een apart ambacht. De oudste graffiguren uit China dateren van de late Zhou-periode (475-221 v.Chr.). In de Han-dynastie (206 v.Chr-220 n.Chr.) waren er ateliers in het noorden rondom de (hoofd)steden Chang'an en Luoyang, en in de meer zuidwestelijk gelegen provincie Sichuan. De noordelijke ateliers doorstonden veranderde kunstopvattingen en vernieuwingen van technologie; de donkere, groenbruine glazuur van de Han-beeldjes verdween en tijdens de Sui-dynastie (581-618) domineerde de heldere crèmekleurige glazuur. In de hoogtijdagen van de Tang werden graffiguren hoofdzakelijk gedecoreerd in aardekleuren rood, bruin, groen, blauw, geel en wit glazuur. Niet alleen kleuren, maar ook de vormen veranderden drastisch. Waren de figuren van de Sui nog statisch, rond 700 veranderden de beelden onder invloed van westerse kunstopvattingen die China binnenkwamen via de zijderoute: de figuren werden naturalistischer en groter (de zes grafbewakers waren doorgaans groter dan overige

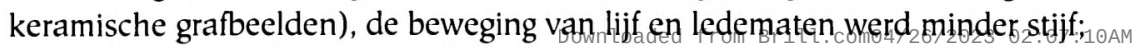
kleding, wapengerei en gezichtsuitdrukkingen werden realistischer via free access 


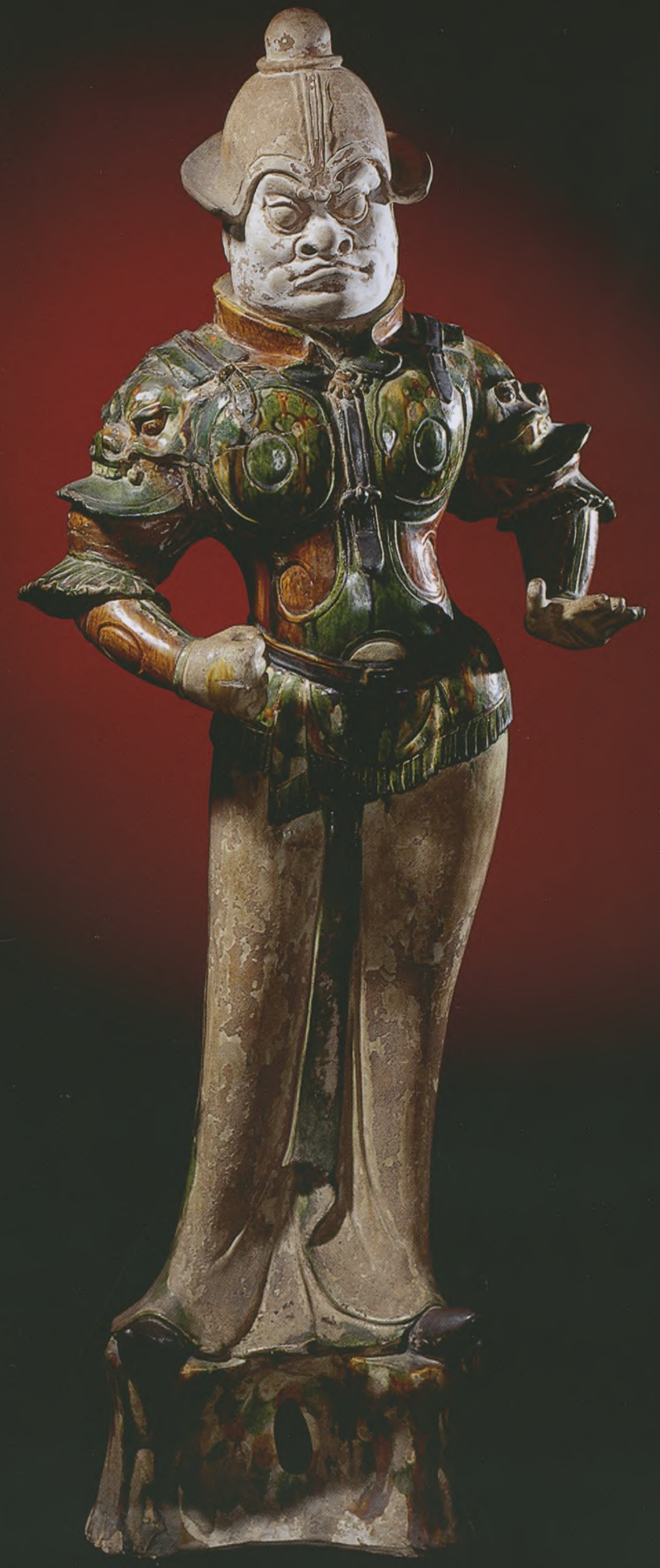




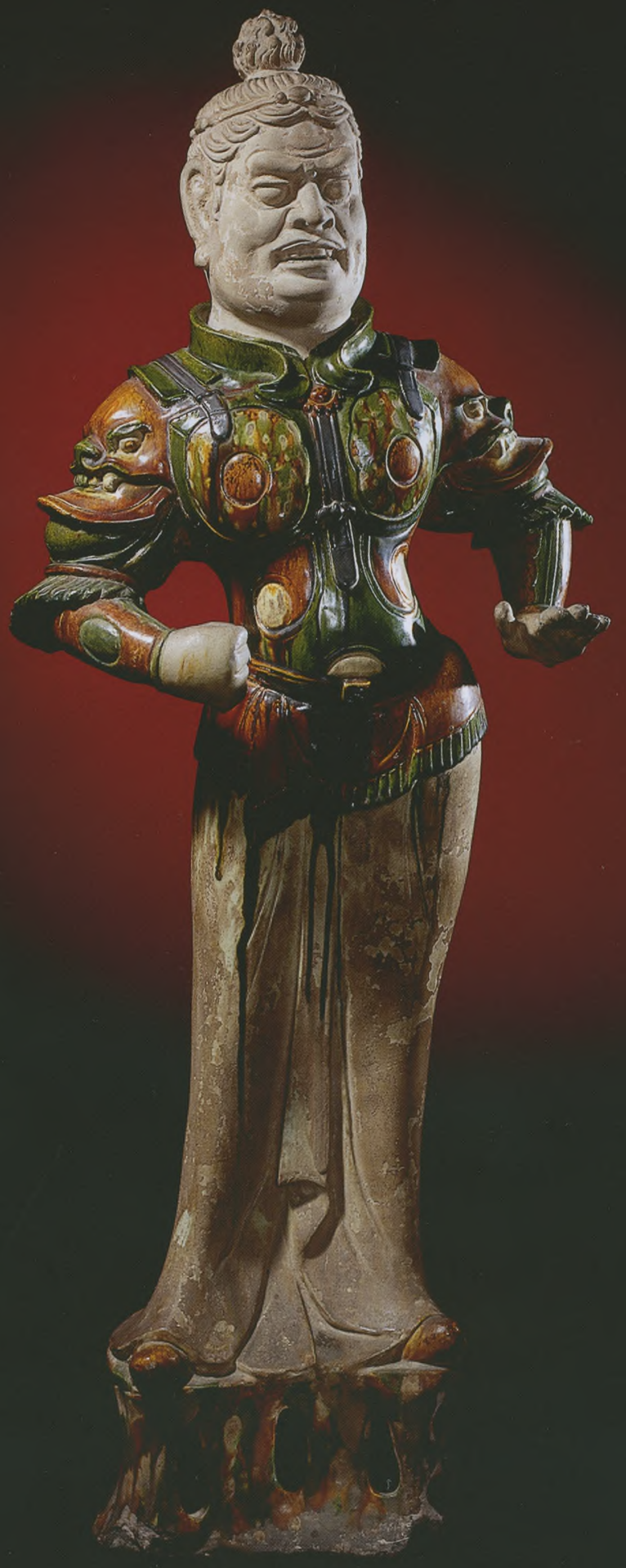


weergegeven. Daarnaast verschenen er fantasiewezens, een soort bovenmenselijke monsters. Langzaamaan veranderden militaire beeldjes van naturalistische weergegeven mannen in shenjiang (hemels generaals) en tianwang (hemelse koningen) (afb. 5).

Halverwege de $8^{\mathfrak{c}}$ eeuw maakte een tienjarige opstand (An Lushan Rebellie, 756-766) een eind aan de bloei van de zogenaamde sancai-figuren en werd het overgrote deel van de ateliers vernietigd.

\section{'Sancai'}

Afgezien van het gezicht waren de grafbewakers geglazuurd in sancai (drie kleuren) loodglazuur, de bonte kleurencombinatie van gekleurd glazuur die zo kenmerkend is voor de decoratie van Tang-keramiek. ${ }^{2}$ Het decoreren van aardewerk met glazuur bestond al in de Han. Glazuren was een veel gebruikte techniek in de $3^{\mathrm{e}}-7^{\mathrm{e}}$ eeuw. Maar de meerkleurigheid alsook de schitterend uitgewerkte vormgeving kenden hun hoogtijdagen in de Tang.

Sancai-glazuurtechniek is een polychroom glazuren decoratie op aardewerk. In voorgaande dynastieën was aardewerk gesierd met een monochroom glazuur. Tang-ambachtslieden experimenteerden veel met het mengen van diverse glazuurkleuringen. Oorspronkelijk waren de kleuren gebaseerd op drie verschillende zuurstofverbindingen: ijzeroxide gaf geelbruin, koperoxide werd groen (soms oranjebruin) en kobaltoxide leverde blauw op. De beelden werden voor het bakproces met gekleurd glazuur beschilderd met uitzondering van het gezicht dat later 'koud' werd behandeld. Door het met de hand in te kerven werd individualiteit aan de beelden gegeven. Ieder beeld had daarom een eigen gezicht.

Er bestonden ten tijde van de Tang strenge voorschriften met bepalingen over aantallen, afmetingen en de positie van de figuren ten opzichte van het graf. Dat was voor de ateliers geen probleem omdat men de beelden in serie vervaardigde. Elk atelier had vormstukken (mallen) van diverse onderdelen van graffiguren die in verschillende combinaties konden worden toegepast. De losse delen werden vervolgens met kleislib aan elkaar gelijmd. Tangkeramiek werd dus als massaproduct vervaardigd waarbij was voorgeschreven wat passend was in welke specifieke situatie.

\section{Van Rossums wachters}

De wachters die Van Rossum legateerde aan onze Vereniging zijn gemaakt van aardewerk en deels geglazuurd ( $\mathrm{afb}$. 3 en 4). Ze zijn beide 85 centimeter hoog. De wachters dragen bovenkleding die is gekleurd volgens de sancaiglazuurtechniek. Ondanks een afwijkende kleursamenstelling zijn de jakken identiek. Op de schouders zien we de koppen van dreigende roofdieren. De lichamen staan in dezelfde pose met een draaiing in de taille en in de schouders. Beide armen zijn gebogen waarbij de linkerhand met de handpalm naar de grond wijst alsof de hand ergens op rust, terwijl de rechterhand tot een vuist is gebald alsof deze een wapen of een stok omklemt. Ook de sokkel, de stand van de voeten en de beenbekleding zijn gelijk, maar hun hoofden verschillen sterk van elkaar. Het gezicht en de hoofdtooi zijn vrij van glazuur. Eén wachter draagt een helm met ees opstaande rand en bovegnop 0 : 10Am een bolvormige knop. Hij heeft een bolle stompe neus en zijn nek is ${ }^{\vee n i e t}{ }^{r e e}$ access 


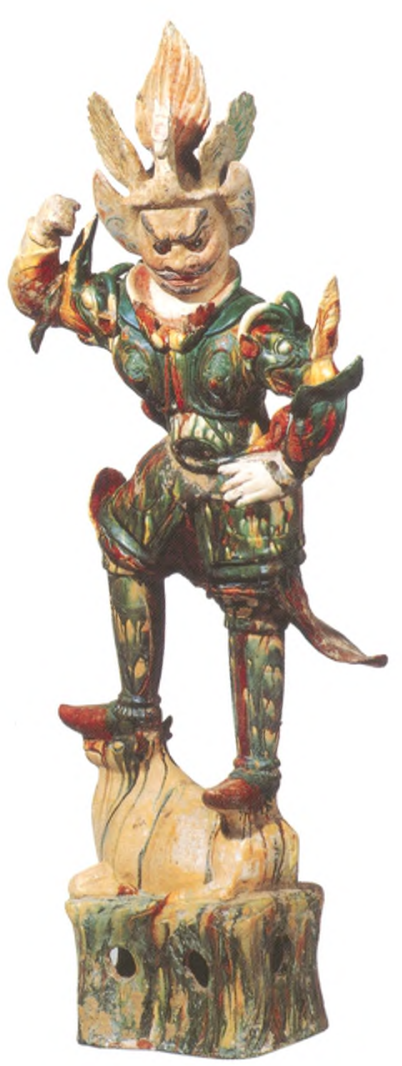

Afbeelding 5

Tianwang (hemelse koning), graffiguur, aardewerk met sancai-glazuur, China, Tangdynastie. Uit: M. Scarpari, Het oude China, 2000.
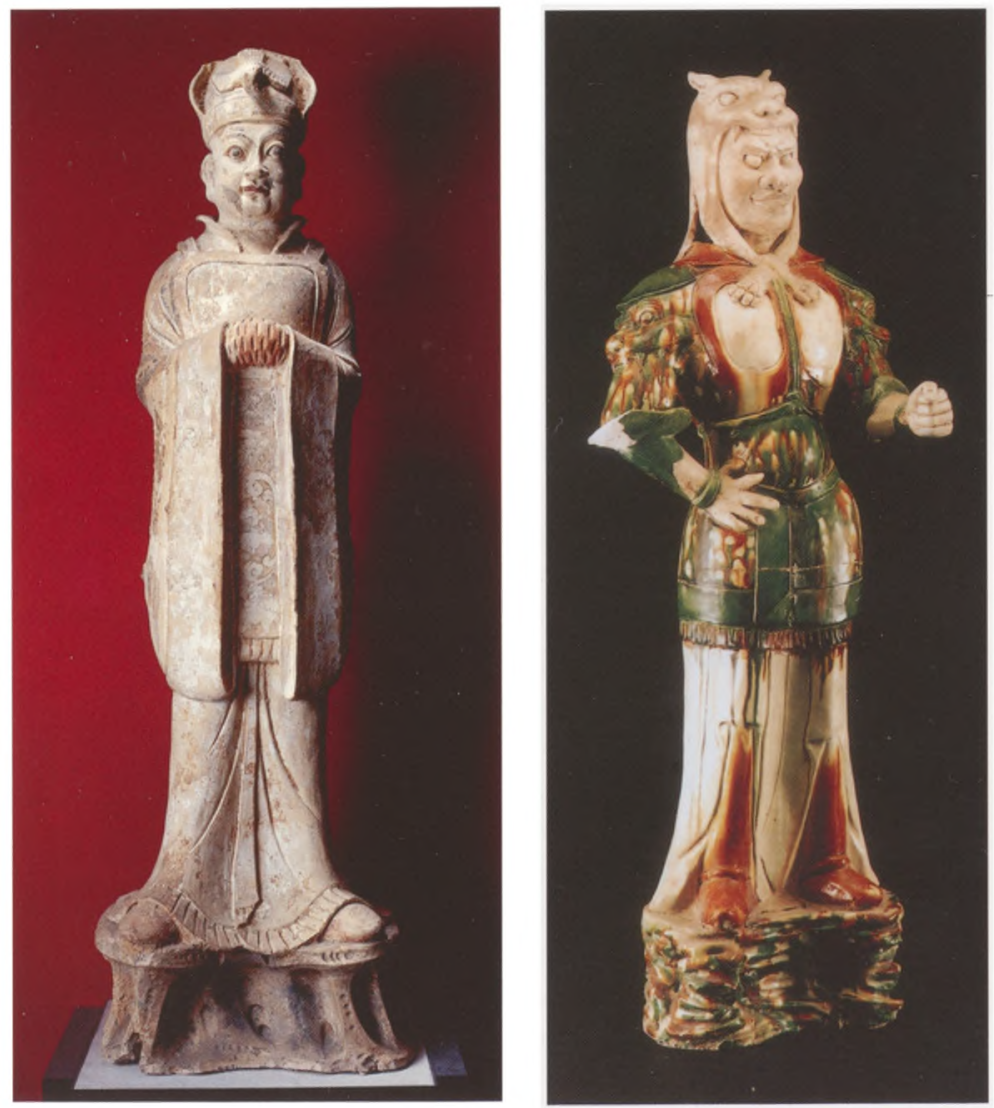

Afbeelding 6

Graffiguur van een ambtenaar, aardewerk met sancai-glazuur en polychromie, hoogte $102 \mathrm{~cm}$., China, Tang-dynastie, schenking van J.E. Westendorp-Osieck in 1945, Rijksmuseum Amsterdam, collectie WAK, AK-MAK-81

\section{Afbeelding 7}

Militaire grafwachter, aardewerk met sancai-glazuur, hoogte $88 \mathrm{~cm}$., gevonden in een graf in Hongqing (voorstad van Xi' an), China, Tang-dynastie. Uit: Sanqin guibao. Shaanxi xin faxian wenwu jinghua.

zichtbaar. De andere wachter heeft een haarknot, een scherpe neus en zijn mond is licht geopend waardoor zijn boventanden zichtbaar zijn. De bolle ogen en grote neuzen zijn duidelijk ontstaan onder westerse invloed.

Het gewaad dat de benen bedekt, moet destijds gedecoreerd zijn geweest. Polychromie is nu niet meer zichtbaar op deze twee wachterfiguren. Om te weten hoe de decoratie er wellicht uitzag, kijken we naar twee andere grafbeelden uit die tijd. Het eerste is een beeld dat de Vereniging in 1945 heeft gekregen van mevrouw J.E. Westendorp-Osieck, ter herinnering aan haar overleden echtgenoot ( $\mathrm{afb}$. 6). Ook deze ambtenaar vormt de helft van een tweetal. Op zijn ondergewaad zien we rode en goudkleurige polychromie, met prachtige krullen en bloemmotieven, herkenbaar uit de schilderkunst van die tijd.

Een andere tijdgenoot is ook een militair. Het grafbeeld is - weer met uitzondering van het gezicht - volledig geglazuurd. Ook zijn beenbekleding en laarzen zijn geglazuurd volgens de sancai-techniek. Hij is wat korter dan access 
de wachters van Van Rossum. Zijn bovenjak heeft vergelijkbare dreigende dierenkoppen op de schouders. Ook zijn hoofd vertoont overeenkomsten met de wachters die zijn gelegateerd aan de Vereniging: ronde ogen en een grote, scherpe neus. Zijn hoofddeksel bestaat uit een tijgerkop (afb. 7).

We zullen nooit met stelligheid weten hoe de benen van de wachters van Van Rossum gedecoreerd waren. We kunnen wel vaststellen dat hun verschijning in alle opzichten beantwoordde aan de eisen van hun tijd. De militaire grafwachters zien er stevig en afschrikwekkend uit en voldeden beslist aan hun opdracht om ongewenste bezoekers aan het graf af te schrikken.

\section{Geraadpleegde literatuur}

- J. van Campen en M. Fitski, 'Recente aanwinsten van de afdeling Aziatische Kunst, Twee wachterfiguren', Aziatische Kunst 33/4 ( 2003), p. 12.

- L. Hájek en W. Forman, A Book of Chinese Art. Four thousand years of sculpture, painting, bronze, jade, lacquer and porcelain, Londen, 1966.

- P. Lunsingh Scheurleer (red.), Asiatic Art in the Rijksmuseum, Amsterdam, Amsterdam, 1985.

- J. Hildebrand, Erfenis van oude culturen. China, Alphen aan den Rijn, 1987.

- J. Rawson, The British Museum Book of Chinese Art, New York, 1996.

- Sanqin guibao. Shaanxi xin faxian wenwu jinghua, Xi' an, 2001.

- W. Speiser, China. Geist und Gesellschaft, Baden-Baden, 1974.

- W. Watson, The Art of China to AD 900, New Haven, 1995.

- Zhongguo taoci mingpin zhenshang congshu. Tang Sancai, Shanghai Renmin Meili Chubanshe

\section{Noten}

1. Met dank aan mevrouw A. Vos-van de Waal en de heren F.G.J. Jennekens en $\mathrm{H}$. Sakkers voor hun gegevens over de heer Van Rossum en aan de heer W.L. Harthoorn voor zijn waardevolle taalkundige adviezen.

2. Sancai begon zijn bloeiperiode tijdens de regeerperiode van de Tang-keizer Gaozong (649-683) en bereikte zijn hoogtepunt in de Kaiyuan-periode (713-742, $2^{\mathrm{e}}$ periodenaam van de Tang-keizer Xuanzong). Met name de sancai-figuren kenden een hoge kwaliteit met prachtige kleurenspel en verschillende stijlen en levendige gezichtsuitdrukkingen. Na de Tianbao-periode (741-756, $3^{\mathrm{e}}$ periodenaam van keizer Xuanzong) nam de productie van sancai-keramiek sterk af. 